\title{
SENSITIVITY OF MASS TRANSFER-BASED EVAPORATION EQUATIONS TO ERRORS IN DAILY AND MONTHLY INPUT DATA
}

\author{
V. P. SINGH ${ }^{1}$ AND C.-Y. XU ${ }^{2 *}$ \\ ${ }^{1}$ Department of Civil and Environmental Engineering, Louisiana State University, Baton Rouge, LA 70803-6405, USA \\ ${ }^{2}$ Division of Hydrology, Uppsala University, Norbyvägen 18B, S-75236 Uppsala, Sweden
}

\begin{abstract}
The influence of data errors on the performance of mass transfer-based evaporation equations was investigated for both monthly and daily data from a climatological station in the State of Vaud in Switzerland. Evaporation estimates were found to be particularly sensitive to vapour pressure gradient, less sensitive to wind speed and most insensitive to temperature. A quantitative analysis showed that: (1) systematic errors in vapour pressure data influenced evaporation estimates inversely to more or less the same magnitude for both monthly and daily cases; (2) systematic errors in wind speed and temperature data influenced evaporation estimates inversely to the magnitude of about a half and a quarter of the magnitude of the influence of vapour pressure errors, respectively; and (3) evaporation estimates were much more sensitive to random errors in the case of monthly data than daily data. (C) 1997 John Wiley \& Sons Ltd.
\end{abstract}

Hydrol. Process., Vol. 11, 1465-1473 (1997).

(No. of Figures: 6 No. of Tables: 5 No. of Refs: 33)

KEY WORDS evaporation; mass-transfer method; sensitivity analysis of data errors

\section{INTRODUCTION}

Evaporation estimates are essential for water balance studies, irrigation and land resources planning, etc. Of all the components of the hydrological cycle, evaporation is perhaps the most difficult to estimate owing to complex interactions between the components of the land-plant-atmosphere system.

There exists a multitude of methods for the measurement and estimation of evaporation. Overviews of many of these methods are found in review papers or books (e.g. Brutsaert, 1982; Singh, 1989; Morton, 1990, 1994). The methods for determining evaporation can be grouped into several categories, including: (1) empirical (e.g. Kohler et al., 1955), (2) water budget (e.g. Guitjens, 1982), (3) energy budget (e.g. Fritschen, 1966), (4) mass transfer (e.g. Harbeck, 1962), (5) combination (e.g. Penman, 1948; Monteith, 1965; Shuttleworth and Wallace, 1984), and (6) measurement (e.g. Young, 1947). In a recent paper by Singh and Xu (1997) advantages and disadvantages of various methods were discussed. The foremost physically based evaporation model for closed vegetation surfaces is arguably the Monteith development of the Penman equation (Monteith, 1965), or the Shuttleworth-Wallace model (Shuttleworth and Wallace, 1984) which extends the work of Monteith for use in sparse covers. However, because of their requirements for detailed meteorological data, such as net radiation, sensible heat flux etc., they are suitable in small areas for research purposes only, their practical utility for larger areas is limited. Considering the fact that the mass transfer equations (Table I) are still widely used in engineering practice, the quantification of the sensitivity of these formulae to their driving variables is useful and needed. An inspection of these equations reveals that the only meteorological factors having a major influence on evaporation are vapour pressure gradient, wind speed and temperature. Air pressure, fluid density and water surface elevation for a given location may not greatly affect the rate of change of evaporation. Because $e_{\mathrm{s}}$ (maximum vapour pressure at the

\footnotetext{
* To whom correspondence should be addressed.
} 
Table I. Some mass transfer-based evaporation equations for estimation of evaporation

\begin{tabular}{|c|c|c|c|}
\hline $\begin{array}{l}\text { Equation } \\
\text { no. }\end{array}$ & Author & Equation & Remarks \\
\hline (1) & Dalton (1802) & $E(\mathrm{in} . / \mathrm{mo})=a\left(e_{\mathrm{s}}-e_{\mathrm{a}}\right)$ & $\begin{array}{l}a=15 \text { for small, shallow water, } \\
\text { and } a=11 \text { for large deep water }\end{array}$ \\
\hline (2) & Fitzgerald (1886) & $E(\mathrm{in} . / \mathrm{mo})=(0.4+0.199 u)\left(e_{\mathrm{s}}-e_{\mathrm{a}}\right)$ & \\
\hline (3) & Meyer (1915) & $E(\mathrm{in} . / \mathrm{mo})=11(1+0 \cdot 1 u)\left(e_{\mathrm{s}}-e_{\mathrm{a}}\right)$ & $\begin{array}{l}e_{\mathrm{a}} \text { is measured at } 30 \mathrm{ft} \text { above the } \\
\text { surface }\end{array}$ \\
\hline (4) & Horton (1917) & $E(\mathrm{in} . / \mathrm{mo})=0.4\left[(2-\exp (-2 u))\left(e_{\mathrm{s}}-e_{\mathrm{a}}\right)\right]$ & \\
\hline (5) & Rohwer (1931) & $\begin{array}{l}E(\text { in. } / \mathrm{da})=0.77\left(1.465-0.0186 p_{\mathrm{b}}\right) \\
\quad \cdot(0.44+0.118 u)\left(e_{\mathrm{s}}-e_{\mathrm{a}}\right)\end{array}$ & $\begin{array}{l}p_{\mathrm{b}}=\text { barometric pressure } \\
\text { in in. of } \mathrm{Hg}\end{array}$ \\
\hline (6) & Penman (1948) & $E(\mathrm{in} . / \mathrm{da})=0.35\left(1+0.24 u_{2}\right)\left(e_{\mathrm{s}}-e_{\mathrm{a}}\right)$ & \\
\hline (7) & Harbeck et al. (1954) & $\begin{array}{l}E(\text { in. } / \text { da })=0.0578 u_{8}\left(e_{\mathrm{s}}-e_{\mathrm{a}}\right) \\
E(\text { in. } / \text { da })=0.0728 u_{4}\left(e_{\mathrm{s}}-e_{\mathrm{a}}\right)\end{array}$ & \\
\hline (8) & Kuzmin (1957) & $E($ in. $/, \mathrm{mo})=6 \cdot 0\left(1+0 \cdot 21 u_{8}\right)\left(e_{\mathrm{s}}-e_{\mathrm{a}}\right)$ & \\
\hline (9) & Harbeck et al. (1958) & $\begin{array}{l}E(\text { in. } / \mathrm{da})=0.001813 u\left(e_{\mathrm{s}}-e_{\mathrm{a}}\right) \\
\quad \cdot\left(1-0.03\left(T_{\mathrm{a}}-T_{\mathrm{w}}\right)\right)\end{array}$ & $\begin{array}{l}T_{\mathrm{a}}=\text { average air temperature }{ }^{\circ} \mathrm{C} \\
+1.9^{\circ} \mathrm{C} ; T_{\mathrm{w}}=\text { average water } \\
\text { surface temperature, }{ }^{\circ} \mathrm{C}\end{array}$ \\
\hline (10) & Konstantinov (1968) & $E(\mathrm{in} . / \mathrm{da})=\left[0.024\left(t_{\mathrm{w}}-t_{2}\right) / u_{1}+0.166 u_{1}\right]\left(e_{\mathrm{s}}-e_{\mathrm{a}}\right)$ & \\
\hline (11) & Romanenko (1961) & $E(\mathrm{~cm} / \mathrm{mo})=0 \cdot 0018\left(T_{\mathrm{a}}+25\right)^{2}(100-h n)$ & $h n=$ relative humidity \\
\hline (12) & Sverdrup (1946) & $E(\mathrm{~cm} / \mathrm{s})=\frac{0 \cdot 623 \rho K_{0}^{2} u_{8}\left(e_{0}-e_{8}\right)}{p[\ln (800 / z)]^{2}}$ & $\begin{array}{l}K_{0}=\text { von Karman's const } \\
\rho=\text { density of air } \\
p=\text { atmosphere pressure }\end{array}$ \\
\hline (13) & $\begin{array}{l}\text { Thornthwaite and } \\
\text { Holzman (1939) }\end{array}$ & $E(\mathrm{~cm} / \mathrm{s})=\frac{0 \cdot 623 \rho K_{0}^{2}\left(u_{8}-u_{2}\right)\left(e_{2}-e_{8}\right)}{p[\ln (800 / 200)]^{2}}$ & \\
\hline
\end{tabular}

The wind speed (monthly mean), $u$, is measured in miles per hour and vapour pressure, $e$, in inches of $\mathrm{Hg}$. The subscripts attached to $u$ refer to height in metres at which the measurements are taken; no subscript refers to measurements near the ground or water surface

temperature of the water surface) is unknown, the term $\left(e_{\mathrm{s}}-e_{\mathrm{a}}\right)$ in the equations of Table $\mathrm{I}$ is replaced by $\left(e_{0}-e_{\mathrm{a}}\right)$, the saturation deficit of the air (Visentini, 1936; Haude, 1955; Hounam, 1971; Singh and Xu, 1997), where $e_{0}$ is the saturation vapour pressure at the air temperature. Likewise, the water surface temperature used in the equations is replaced by the dew point temperature, $T_{\mathrm{d}}$. On the basis of the above discussion, the evaporation equations given in Table I can be generalized into seven equations (Table II).

It is generally accepted that empirical formulae, as presented in Table I, may be reliable in the areas and over the periods for which they were developed, but large errors can be expected when they are extrapolated to other climatic areas without recalibrating the constants involved in the formulae (Hounam, 1971). In order to alleviate these difficulties, a comparative study was carried out to evaluate the seven generalized equations as shown in Table II instead of comparing the original formulae as shown in Table I. This consideration has, at least, two advantages: (1) for a specific site of interest, it is the form of a given model that is more important (useful) than the predetermined values of the constants using the meteorological data measured at different sites, and (2) it allows comparison of all the model forms using the standard meteorological data measured at the same heights and for the same periods.

This paper reports a part of the investigation on examining the sensitivity of the mass transfer-based evaporation equations to input data errors. The earlier stage of the study was presented in Singh and $\mathrm{Xu}$ 
Table II. Seven generalized mass transfer-based evaporation equations

Generalized equations

(14) $E=a_{1} \cdot\left(e_{0}-e_{\mathrm{a}}\right)$

(15) $E=a_{1} \cdot u \cdot\left(e_{0}-e_{\mathrm{a}}\right)$

(16) $E=a_{1} \cdot(1-\exp (-u)) \cdot\left(e_{0}-e_{\mathrm{a}}\right)$

(17) $E=a_{1} \cdot\left(1+a_{2} \cdot u\right) \cdot\left(e_{0}-e_{\mathrm{a}}\right)$

(18) $E=a_{1} \cdot u \cdot\left(e_{0}-e_{\mathrm{a}}\right) \cdot\left(1-a_{2} \cdot\left(T_{\mathrm{a}}-T_{\mathrm{d}}\right)\right)$

(19) $E=a_{1} \cdot\left(T_{\mathrm{a}}+25\right)^{2} \cdot(100-h n)$

(20) $E=a_{1} \cdot\left(1+a_{2} \cdot u\right) \cdot\left(e_{0}-e_{\mathrm{a}}\right) \cdot\left(1-a_{3} \cdot\left(T_{\mathrm{a}}-T_{\mathrm{d}}\right)\right)$
Original equations

Dalton (1802)

Harbeck et al. (1954)

Horton (1917)

Fitzgerald (1886), Meyer (1915), Rohwer (1931), Penman (1948), Kuzmin (1957), Sverdrup (1946), Thornthwaite and Holzman (1939)

Harbeck et al. (1958)

Romanenko (1961)

A generalized equation

$a_{1}, a_{2}$ and $a_{3}$ are parameters; $h n$ is the relative humidity; and other symbols have the same meaning as mentioned in the text

(1997) where the concept of the various methods, the statistical methodology used for model evaluation and the application results to four climatological stations in north-western Ontario, Canada were discussed. One of the conclusions of the earlier paper indicated qualitatively that the saturation deficit of the air is the dominant factor in estimating monthly free water-surface evaporation, and significant errors of evaporation estimates can be expected if there are errors in input data of vapour pressure. Wind speed and temperature were found to be insignificant factors. However, more quantitative analysis must be performed before such generalized conclusions can assist application of these equations. A survey of the literature shows that despite the popularity of the evaporation estimation approaches, there appears to have been little attempt to evaluate the magnitude of their estimation errors due to input errors. To a large extent, this failure to evaluate error can be attributed to the reliance of evaporation equations on a wide range of physical input variables, all subject to varying degrees of experimental and systematic measurement errors. Wales-Smith (1971) evaluated the sensitivity of the Penman equation to input data errors. McCulloch (1965) discussed the reliability of the evaporation equation with regard to an observational network, and Howard and Lloyd (1979) studied the sensitivity of parameters in the Penman evaporation equation and direct recharge balance. Beven (1979) reported a study of the sensitivity of the Penman-Monteith equation for estimating actual evapotranspiration rates to errors in parameter values and input data. Little attention has, however, been paid to the possible cumulative effects of individual input parameter errors to other evaporation estimation methods.

In this study, the following questions were addressed. How do the mass transfer-based evaporation equations compare if there are errors in the input data? Which input variable may need extra caution? To what extent may the errors result in significant influence on model performance? In each case both monthly and daily time series were studied and compared.

\section{STUDY REGION AND DATA}

The Changins climatological station in the State of Vaud in Switzerland was used in this study. This station is located at a latitude of $46^{\circ} 24^{\prime} \mathrm{N}$ and a longitude of $06^{\circ} 14^{\prime} \mathrm{E}$. Several hydrometeorological variables including air temperature, dew point temperature, relative humidity, wind speed, vapour pressure and evaporation, among others, have been continuously recorded for the period 1990-1994. The hourly data were taken and subsequently integrated to the daily values for use in the study. The following units for these variables were used: evaporation, $E$, in $\mathrm{mm} / \mathrm{month}$; saturation and actual vapour pressures, $e_{0}$ and $e_{\mathrm{a}}$, in mbar; wind speed measured at a height of $2 \mathrm{~m}, u$, in $\mathrm{m} / \mathrm{s}$; and air temperature and dew point temperature measured at a height of $2 \mathrm{~m}, T_{\mathrm{a}}$ and $T_{\mathrm{d}}$, in ${ }^{\circ} \mathrm{C}$. The monthly averages of the main climatic parameters and the amount of evaporation are given in Table III. 
Table III. Monthly averages of main climatic variables and evaporation at station Changins (1990-1994)

\begin{tabular}{|c|c|c|c|c|c|c|}
\hline \multirow[t]{2}{*}{ Month } & \multirow{2}{*}{$\begin{array}{l}\text { Air temperature } \\
\qquad\left({ }^{\circ} \mathrm{C}\right)\end{array}$} & \multirow{2}{*}{$\begin{array}{l}\text { Wind speed } \\
(\mathrm{m} / \mathrm{s})\end{array}$} & \multirow{2}{*}{$\begin{array}{l}\text { Humidity } \\
(\%)\end{array}$} & \multicolumn{2}{|c|}{ Vapour pressure } & \multirow{2}{*}{$\begin{array}{l}\text { Evaporation } \\
\text { (mm) }\end{array}$} \\
\hline & & & & Saturation & Actual & \\
\hline January & $2 \cdot 19$ & 0.68 & $80 \cdot 50$ & $7 \cdot 19$ & $5 \cdot 72$ & $29 \cdot 28$ \\
\hline February & $2 \cdot 77$ & 0.68 & $78 \cdot 25$ & $7 \cdot 56$ & 5.81 & $32 \cdot 01$ \\
\hline March & $7 \cdot 47$ & 0.72 & $69 \cdot 22$ & $10 \cdot 41$ & $7 \cdot 04$ & 67.05 \\
\hline April & 8.98 & 0.75 & 67.76 & 11.49 & $7 \cdot 50$ & 83.40 \\
\hline May & $14 \cdot 30$ & 0.72 & $68 \cdot 19$ & $16 \cdot 38$ & 10.73 & $106 \cdot 77$ \\
\hline June & $16 \cdot 70$ & 0.71 & $70 \cdot 74$ & $19 \cdot 04$ & 13.06 & $104 \cdot 10$ \\
\hline July & $20 \cdot 14$ & 0.67 & $66 \cdot 08$ & $23 \cdot 65$ & $15 \cdot 07$ & $146 \cdot 32$ \\
\hline August & $20 \cdot 53$ & 0.67 & $63 \cdot 84$ & $24 \cdot 17$ & $14 \cdot 81$ & 152.25 \\
\hline September & $15 \cdot 28$ & 0.61 & $75 \cdot 05$ & $17 \cdot 42$ & $12 \cdot 72$ & $82 \cdot 59$ \\
\hline October & $10 \cdot 03$ & 0.65 & $81 \cdot 16$ & $12 \cdot 36$ & $9 \cdot 91$ & $43 \cdot 71$ \\
\hline November & $6 \cdot 04$ & 0.61 & $82 \cdot 65$ & $9 \cdot 44$ & 7.76 & $28 \cdot 75$ \\
\hline December & 2.75 & 0.85 & $80 \cdot 37$ & 7.49 & $6 \cdot 00$ & 31.76 \\
\hline
\end{tabular}

\section{PARAMETER ESTIMATION AND EVALUATION CRITERION}

The model application includes the specification of model type, determination of model parameters and verification of model performance. In this section only a limited number of items are discussed. A full account is given by Singh and $\mathrm{Xu}(1997)$.

To estimate model parameters, an 'automatic optimization' method was used, and the criterion for optimization adopted was the least-square error between measured and computed free water evaporation. Let $E_{t, \mathrm{obs}}$ be the observed evaporation, and $E_{t, \text { comp }}$ the computed evaporation, which is a function of model parameters. Then, the objective function, $E R$, to be minimized can be expressed as

$$
E R=\Sigma\left(E_{t, \mathrm{obs}}-E_{t, \mathrm{comp}}\right)^{2} \rightarrow \operatorname{minimum} S S Q
$$

where summation is over the number of observations. Optimization of model parameters is the minimization of the objective function in Equation (21).

Various measures of goodness-of-fit have been proposed, two of them were employed in the study: (1) minimum sum of squares $(S S Q)$ as given by Equation (21), and (2) the criterion $R^{2}$ of Nash and Sutcliffe (1970).

\section{Calibration}

\section{RESULTS AND DISCUSSION}

The seven generalized equations given in Table II and the statistical methodology discussed in the previous section were applied to the data of Changins climatological station. The optimized parameter

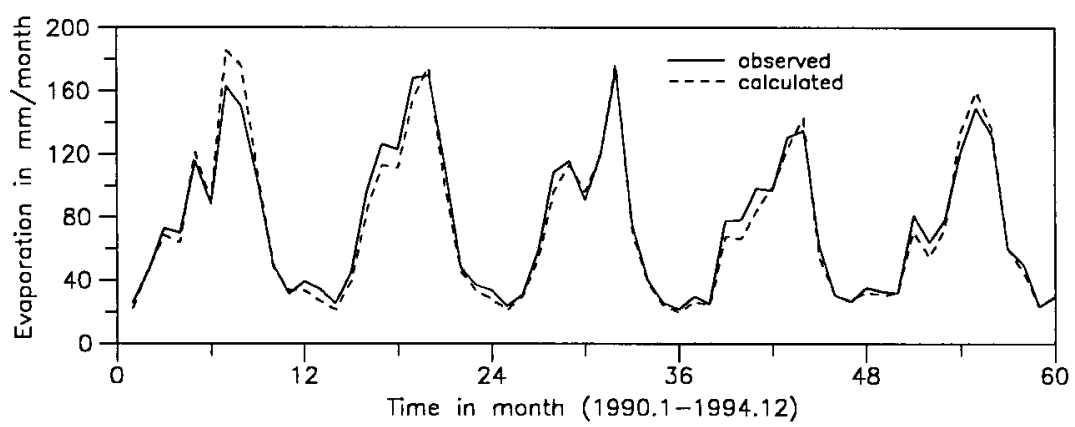

Figure 1. Comparison between observed and calculated monthly evaporation using Equation (20) 
Table IV. Optimized parameter values and $R^{2}$ values for station Changins

\begin{tabular}{|c|c|c|c|c|c|c|c|}
\hline \multirow[t]{2}{*}{ Equation } & \multicolumn{2}{|c|}{$a_{1}$} & \multicolumn{2}{|c|}{$a_{2}$} & \multicolumn{2}{|c|}{$a_{3}$} & \multirow[t]{2}{*}{$R^{2}$} \\
\hline & Value & HWCI & Value & HWCI & Value & HWCI & \\
\hline \multicolumn{8}{|c|}{ Monthly case } \\
\hline 14 & $17 \cdot 49$ & $0 \cdot 675$ & & & & & $0 \cdot 958$ \\
\hline 15 & 6.95 & $0 \cdot 307$ & & & & & 0.946 \\
\hline 16 & $19 \cdot 16$ & 0.685 & & & & & 0.964 \\
\hline 17 & $10 \cdot 55$ & $4 \cdot 61$ & $0 \cdot 264$ & 0.289 & & & 0.969 \\
\hline 18 & $9 \cdot 25$ & $1 \cdot 26$ & 0.036 & 0.013 & & & 0.963 \\
\hline 19 & $0 \cdot 00207$ & $0 \cdot 00006$ & & & & & 0.977 \\
\hline 20 & $10 \cdot 64$ & 4.78 & 0.420 & $0 \cdot 384$ & 0.029 & $0 \cdot 013$ & 0.978 \\
\hline \multicolumn{8}{|l|}{ Daily case } \\
\hline 14 & $0 \cdot 566$ & $0 \cdot 008$ & & & & & $0 \cdot 868$ \\
\hline 15 & $0 \cdot 192$ & $0 \cdot 004$ & & & & & 0.761 \\
\hline 16 & $0 \cdot 634$ & $0 \cdot 008$ & & & & & 0.904 \\
\hline 17 & $0 \cdot 362$ & $0 \cdot 014$ & $0 \cdot 214$ & 0.022 & & & 0.934 \\
\hline 18 & $0 \cdot 269$ & $0 \cdot 013$ & 0.033 & $0 \cdot 004$ & & & 0.796 \\
\hline 19 & 0.000067 & $0 \cdot 000001$ & & & & & $0 \cdot 898$ \\
\hline 20 & 0.402 & 0.018 & $0 \cdot 249$ & 0.025 & 0.018 & 0.003 & 0.941 \\
\hline
\end{tabular}

HWCI $=$ half width of $95 \%$ confidence interval

values together with the $95 \%$ confidence interval, as well as $R^{2}$ values, are presented in Table IV for both monthly and daily calibrations. For illustrative purposes, a comparison between observed evaporation and the evaporation computed by Equation (20) is shown in Figures 1 and 2 for monthly and daily calibrations, respectively. An examination of Table IV shows that all methods yield comparable results in the monthly case, as can be seen from more or less the same $R^{2}$ values. This confirms the earlier finding that adding more input variables of wind speed and temperature to Equation (14) does not yield significant improvement in estimating monthly evaporation (Singh and $\mathrm{Xu}, 1997$ ). In the daily case, however, Equation (20) is found to be considerably superior to other equations.

\section{Sensitivity of model parameters to input errors}

In order to assess the sensitivity of the evaporation equation to input errors the monthly and daily programmes were run a number of times, each with a different modification to the chosen input. Three categories of general input were examined, the vapour pressure gradient, $\left(e_{0}-e_{\mathrm{a}}\right)$, the wind speed, $u$, and the temperature gradient, $T_{\mathrm{a}}-T_{\mathrm{d}}$. In each case, the original data file (considered as error free) was corrupted by adding 5,10 and $20 \%$ of systematic and random errors. Both positive and negative systematic errors were con-

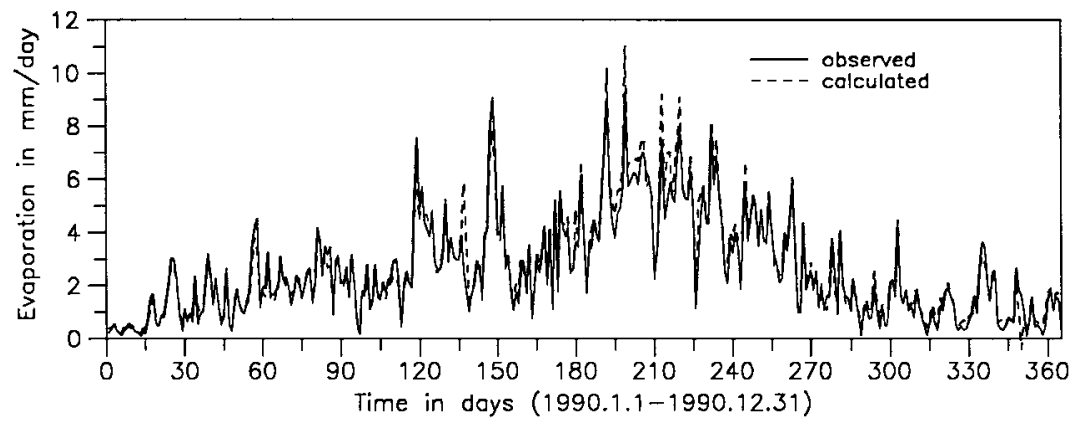

Figure 2. Composition between observed and calculated daily evaporation using Equation (20) 
Table V. Sensitivity of parameter values to input data errors

$\%$ error of input data of
$\%$ error of parameter values resulting from input data errors of

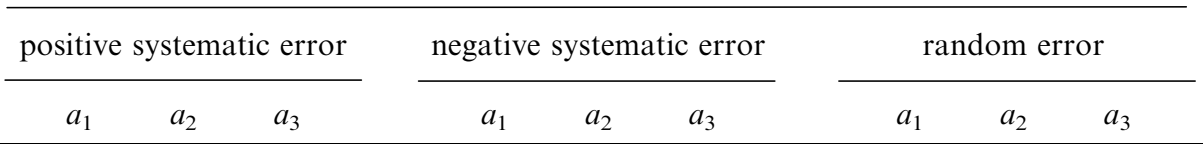

Monthly case

Temperature

5
10
20

Vapour pressure 5 10 20

Wind speed<smiles>[Li][Mg]</smiles>

20

Daily case

Temperature

$$
5
$$

10

20

Vapour pressure 5

10

20

Wind speed

5
5
10
20

20

$\begin{array}{rrr}0 & 0 & 5 \\ 0 & 0 & 11 \\ 0 & 0 & 24\end{array}$

\section{0}

$\begin{array}{lll}0 & 0 & -8\end{array}$

$\begin{array}{lll}0 & -8 \\ 0 & 0 & -16\end{array}$

$\begin{array}{rrr}1 & -2 & 1 \\ 2 & -6 & -1 \\ 4 & -16 & -14\end{array}$

$\begin{array}{rll}5 & 0 & 0 \\ 11 & 0 & 0 \\ 24 & 0 & 0\end{array}$

-4
-9
-16

$\begin{array}{ll}0 & 0 \\ 0 & 0 \\ 0 & 0\end{array}$

$\begin{array}{rrr}-5 & 7 & -11 \\ -11 & 17 & -23 \\ -26 & 47 & -51\end{array}$

$\begin{array}{rrr}0 & 7 & 0 \\ 0 & 12 & 0 \\ 0 & 25 & -1\end{array}$

$\begin{array}{rrr}1 & -4 & -5 \\ 10 & -24 & -14 \\ 36 & -60 & -29\end{array}$

sidered. In this way nine corrupted data series were generated for monthly and daily input series separately. Equation (20) was used in this test to provide a general guideline. This equation was calibrated on each of the nine data series and the parameters were optimized and compared. The results of the analysis are summarized in Table $\mathrm{V}$ for both monthly and daily cases. The most important observations are discussed below.

Influence of systematic errors. (1) Systematic errors of vapour pressure gradient influence parameter $a_{1}$ only, while systematic errors of wind speed and temperature gradient influence parameters $a_{2}$ and $a_{3}$, respectively, as can be expected from the structure of the equation. (2) A given percentage of systematic error results in changes of the same magnitude in the corresponding parameter; for example, introduction of a $10 \%$ error in input data translates into a change in the corresponding parameter of $10 \%$. (3) Input data errors influence the parameter values to the same magnitude for both daily and monthly cases.

Influence of random errors. (1) Introduction of random errors in either of the input variables has influence on all three parameters but with different magnitudes. (2) Random errors of the same magnitude in input data cause much greater changes in parameter values in the monthly case than in the daily case.

\section{Sensitivity of model performance to changes in parameter values}

Qualitative analysis. A qualitative analysis of the parameter sensitivity is performed first by plotting the intersection of the hypersurface of the criterion function $S S Q$ by three planes parallel to the $a_{1^{-}}, a_{2^{-}}$and $a_{3}$-axes in the minimum $\left(\tilde{a}_{1}, \tilde{a}_{2}, \tilde{a}_{3}, S S Q\right)$. The curves must have a parabolic aspect centred around the 


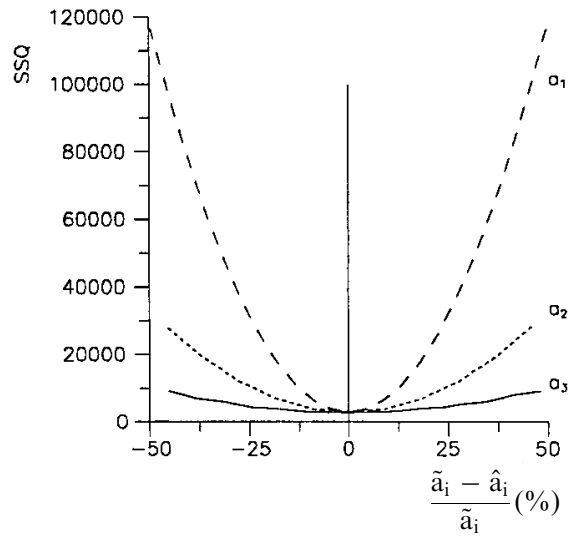

Figure 3. Intersection of the hypersurface of the criterion function, Equation (20), monthly case. ( $\tilde{a}_{1}=$ optimized parameter value, $\hat{a}_{i}=$ parameter values at the neighbourhood of $\tilde{a}_{i}$ )

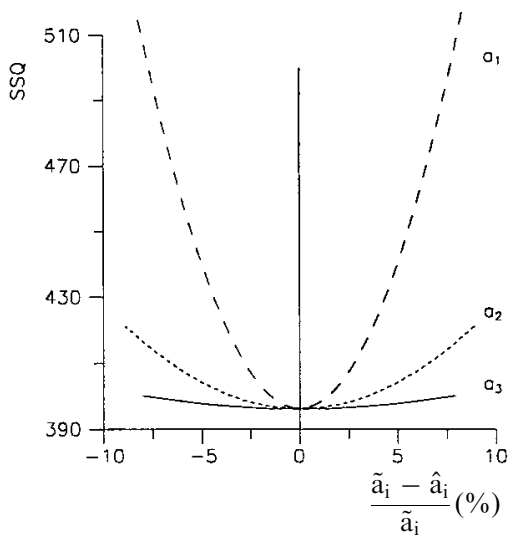

Figure 4. Intersection of the hypersurface of the criterion function, Equation (20), daily case. ( $\tilde{a}_{1}=$ optimized parameter value, $\hat{a}_{i}=$ parameter values at the neighbourhood of $\tilde{a}_{i}$ )

minimum, and, according to the form of the cup, one can make a qualitative analysis of the parameter sensitivity. For illustrative purposes, the effect of changing three parameters on the criterion function $S S Q$ values is shown in Figures 3 and 4 for monthly and daily cases, respectively. It is clearly seen that parameter $a_{1}$ is the most sensitive, while parameter $a_{3}$ is the least sensitive in both cases.

Quantitative analysis. In order to assess the sensitivity of the equation to different parameter values quantitatively, the monthly and daily programmes were run a number of times, each time increasing or decreasing the value of one parameter to a chosen percentage. The calculated mean evaporation values in each case were compared with the mean evaporation value calculated from the 'error free' input data. The results are shown in Figures 5 and 6 for monthly and daily cases, respectively. It is seen that: (1) sensitivity of the evaporation estimation to changes in parameter values shown the same pattern for both monthly and daily cases; (2) the absolute values of relative error in computed evaporation increase linearly with the increase of parameter errors; and (3) the evaporation estimates are most sensitive to parameter $a_{1}$ and least sensitive to parameter $a_{3}$.

Combining Figures 5 and 6 with Table V one finds that: (1) systematic errors in vapour pressure data affect the evaporation estimates inversely to more or less the same magnitude for both monthly and daily cases; (2) systematic errors in wind speed and temperature data affect the evaporation estimates inversely to the magnitude of about a half and a quarter of the magnitude of the influence of vapour pressure errors; and (3) evaporation estimates are much more sensitive to random data errors in the monthly case than in the daily case.

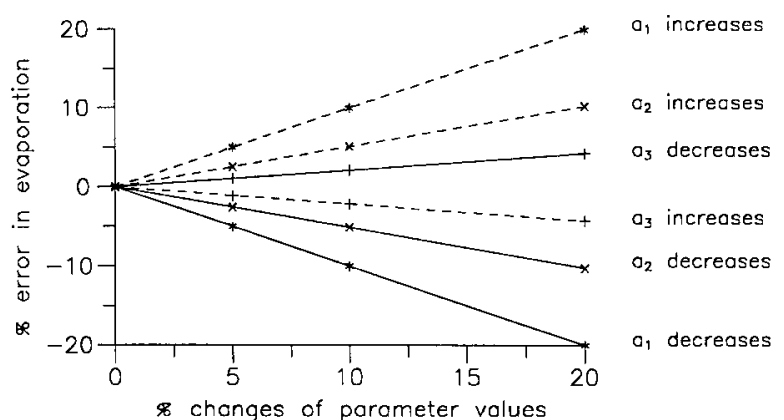

Figure 5. Sensitivity of evaporation estimation to parameter values, Equation (20), monthly case

(C) 1997 John Wiley \& Sons, Ltd.

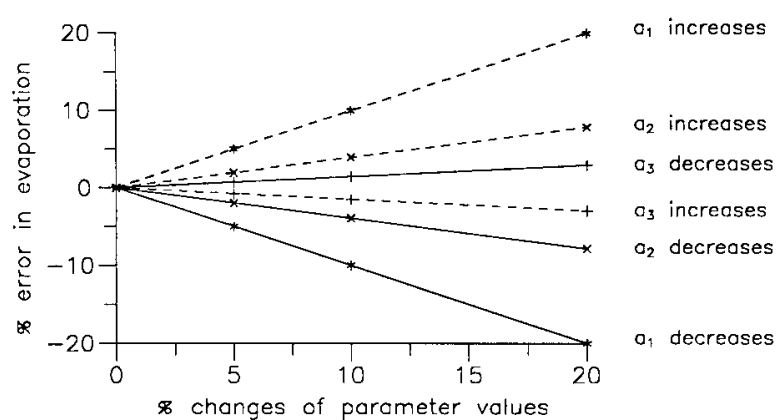

Figure 6. Sensitivity of evaporation estimation to parameter values, Equation (20), daily case

HYDROLOGICAL PROCESSES, VOL. 11, 1465-1473 (1997) 


\section{CONCLUSIONS}

When using the class of equations considered in this paper for evaporation estimation the following conclusions can be drawn.

(1) In estimation of monthly evaporation all equations gave comparable results and the effect of wind speed and temperature on monthly evaporation was marginal. In estimation of daily evaporation, however, Equation (20) was found to be considerably superior to other equations that have a simpler form and use less input data.

(2) Evaporation estimates, in both monthly and daily cases, are most sensitive to vapour pressure data, less sensitive to wind speed and least sensitive to temperature data. Systematic errors in input data influence the evaporation estimates inversely to more or less the same magnitude for both monthly and daily cases, while random errors were found to have a much more significant effect on evaporation estimates in the monthly cases than in the daily case.

The generalized form of evaporation Equation (20) was used as an example for the sensitivity analysis, the findings and conclusions are believed to apply to the individual evaporation equations given in Table I.

\section{ACKNOWLEDGEMENT}

The authors gratefully acknowledge the kind support and services provided by Dr Dominique Berod of IATE-HYDRAM, Switzerland, during data collection.

\section{REFERENCES}

Beven, K. 1979. 'A sensitivity analysis of the Penman-Monteith actual evapotranspiration estimates', J. Hydrol., 44, $169-190$.

Brutsaert, W. 1982. Evaporation into the Atmosphere. D. Reidel Publishing Co., Dordrecht, The Netherlands.

Dalton, J. 1802. 'Experimental essays on the constitution of mixed gases: on the force of steam or vapor from water or other liquids in different temperatures, both in a Torricelli vacuum and in air; on evaporation; and on expansion of gases by heat', Manchester Lit. Phil. Soc. Mem. Proc., 5, 536-602.

Fitzgerald, D. 1886. 'Evaporation', Trans. Am. Soc. Civil Eng., 98(HY12), 2073-2085.

Fritschen, L. J. 1966. 'Energy balance method', Proceedings, American Society of Agricultural Engineers Conference on Evapotranspiration and its Role in Water Resources Management, 5-6 December, Chicago, IL. St. Joseph, MI, pp. 34-37.

Guitjens, J. C. 1982. 'Models of alfalfa yield and evapotranspiration', J. Irrig. Drain. Div., Proc. Am. Soc. Civil Eng., 108(IR3), $212-222$.

Harbeck, G. E. 1962. 'A practical field technique for measuring reservoir evaporation utilizing mass-transfer theory', Geological Survey Professional Paper 272-E. US Government Printing Office, Washington, D.C., pp. 101-105.

Harbeck, G. E., Kohler, M. A., Koberg, G. E., and others. 1954. 'Water loss investigations, Vol. 1, Lake Hefner studies', US Geological Survey Paper 269, (US Government Printing Office), Washington, D.C.

Harbeck, G. E., Kohler, M. A., Koberg, G. E., and others. 1958. 'Water loss investigations, Lake Mead studies', US Geological Survey Paper 298, (US Government Printing Office), Washington, D.C.

Haude, W. 1955. 'Zur Bestimmung der Verdunstung auf möglichst einfacher Weise', Mitteilungen des Deutschen Wetterdienstes, Nr. 11, Band 2, Bad Kissingen.

Horton, R. E. 1917. 'Rainfall interception', Mon. Weather Rev., 47(9), 603-623.

Hounam, C. E. 1971. 'Problems of evaporation assessment in the water balance', Report No. 3 on WMO/IHD Project, WMO, Geneva.

Howard, K. W. F. and Lloyd, J. W. 1979. 'The sensitivity of parameters in the Penman evaporation equations and direct recharge balance', J. Hydrol., 41, 329-344.

Kohler, M. A., Nordenson, T. J., and Fox, W. E. 1955. 'Evaporation from pans and lakes', Weather Bureau Research Paper 38. US Department of Commerce, Washington D.C.

Konstantinov, A. R. 1968. Evaporation in Nature. Leningrad.

Kuzmin, P. O. 1957. 'Hydrophysical investigations of land waters', Int. Assoc. Sci. Hydrol. Publ., 3, 468-478.

McCulloch, J. S. G. 1965. 'Hydrological networks for measurement of evaporation and soil moisture', Proc. Symp. on Design of Hydrological Networks. Int. Assoc. Sci. Hydrol. Publ., 68, 579-584.

Meyer, A. F. 1915. 'Computing runoff from rainfall and other physical data', Trans. Am. Soc. Civil Eng., 79, $1055-1155$.

Monteith, J. L. 1965. 'Evaporation and the environment', Symp. Soc. Expl. Biol., 19, 205-234.

Morton, F. I. 1990. 'Studies in evaporation and their lessons for the environmental sciences', Can. Wat. Res. J., 15(3), $261-285$.

Morton, F. I. 1994. 'Evaporation research - A critical review and its lessons for the environmental sciences', Crit. Rev. Environ. Sci. Technol., 24(3), 237-280. 
Nash, J. E. and Sutcliffe, J. 1970. 'River flow forecasting through conceptual models Part I. A discussion of principles', J. Hydrol., 10, $282-290$.

Penman, H. L. 1948. 'Natural evaporation from open water, bare soil and grass', Proc., R. Soc., London, 193, $120-145$.

Rohwer, C. 1931. 'Evaporation from free water surfaces', Technical Bulletin 271. US Department of Agriculture, Washington, D.C.

Romanenko, V. A. 1961. 'Computation of the autumn soil moisture using a universal relationship for a large area', Proc., Ukrainian Hydrometeorological Research Institute, No. 3, Kiev.

Shuttleworth, W. J. and Wallace, J. S. 1984. 'Evaporation from sparse crops - an energy combination theory', Q. J. R. Meteorol. Soc., 111, 839-855.

Singh, V. P. 1989. Hydrologic Systems, Vol. II, Watershed Modelling. Prentice-Hall, Inc., New York.

Singh, V. P. and Xu, C.-Y. 1997. 'Evaluation and generalization of 13 mass-transfer equations for determining free water evaporation', Hydrol. Proc., 11, 311-324.

Sverdrup, H. U. 1946. 'The humidity gradient over the sea surface', J. Meteorol., 3, 1-8.

Thornthwaite, C. W. and Holzman, B. 1939. 'The determination of land and water surfaces', Mon. Weather Rev., 67, 4-11.

Visentini, M. 1936. International Association of Hydrological Sciences (IAHS) Publication, 22, 119-137.

Wales-Smith, B. G. 1971. 'The use of the Penman formula in hydrology', Hydrol. Mem., No. 39. Meteorological Office, Bracknell, $16 \mathrm{pp}$.

Young, A. A. 1947. 'Evaporation from water surface in California: summary of pan records and coefficients, 1881-1946', Bulletin 54. Public Works Department, Sacramento, California. 